\title{
Rhamnella brachycarpa (Rhamnaceae), a new species from Hainan Island, China
}

\author{
Zhiqiang Lu', Yongshuai Sun' \\ I CAS Key Laboratory of Tropical Forest Ecology, Xishuangbanna Tropical Botanical Garden, Chinese Aca- \\ demy of Sciences, Mengla 666303, Yunnan, China
}

Corresponding author: Yongshuai Sun (sunyongshuai@xtbg.ac.cn)

Academic editor: Hanno Schaefer | Received 4 June 2019 | Accepted 6 August 2019 | Published 26 September 2019

Citation: Lu Z, Sun Y (2019) Rhamnella brachycarpa (Rhamnaceae), a new species from Hainan Island, China. PhytoKeys 132: 19-29. https://doi.org/10.3897/phytokeys.132.36776

\begin{abstract}
Rhamnella brachycarpa Z. Qiang Lu \& Y. Shuai Sun, a new evergreen woody species from Hainan Island, is described and illustrated. The specimens of this new species have previously been identified and placed under $R$. rubrinervis (H. Lév.) Rehder, with which it shares evergreen leaves, erect and climbing habits and axillary flowering branches with bracteole leaves. However, the specimens from three distinct Hainan populations significantly differ from those of $R$. rubrinervis from other regions with smaller length to width ratios of leaves, fruit and seeds, smaller sizes of fruit and seeds and mucronate seed apices. Principal Component Analysis of the closely related taxa, based on multiple morphological characters, further recognised two separated groups. One of them comprises $R$. tonkinensis and $R$. rubrinervis, the other merely includes all individuals from these distinct Hainan populations. Therefore, $R$. brachycarpa, based on these distinct Hainan populations, is here erected as a new species, distinctly different from its published relatives.
\end{abstract}

\section{Keywords}

Rhamnella brachycarpa, new species, Hainan Island

\section{Introduction}

The buckthorn family (Rhamnaceae) comprises 11 tribes and approximately 61 genera (Hauenschild et al. 2016). In this family, Rhamnella (Miquel, 1867) in the tribe Rhamneae is a small genus of shrubs, small trees and climbers (Chen and Carsten 2007; Hauenschild et al. 2016). In "Flora of China", Rhamnella, with eight described species, is recognised by the distinctly pedicellate flowers and fleshy fruits, 1-stoned drupes, pinnately veined leaves, serrate leaf margins, semi-inferior ovaries, stipules without thorns 
and flowers in axillary cymes (Chen and Carsten 2007). Most of them are deciduous broad-leaved woody species with erect habit. According to Flora of China, $R$. rubrinervis (H. Lév.) Rehder is the only evergreen species with both erect and climbing habits within this genus in China and is distributed in S and SE Yunnan, SW and S Guizhou, Guangxi and Hainan Island (Chen and Carsten 2007). However, four other closely related species, $R$. tonkinensis (Pit.) T. Yamaz., $R$. hainanensis Merr., $R$. crenulata (Hand.-Mazz.) T. Yamaz. and $R$. longifolia Tsai \& K.M. Feng, have also been published (http://www. theplantlist.org). Only $R$. rubrinervis and $R$. tonkinensis have been accepted as valid species, while all others are treated as synonyms of $R$. rubrinervis (Chen and Carsten 2007). Interestingly, these evergreen species have been treated as an independent genus because of the unique morphology and $R$. rubrinervis has been proposed to be conspecific to $R$. tonkinensis (Fan and Yang 1997; Chen and Carsten 2007). After examining all specimens of $R$. rubrinervis preserved in the Chinese Virtual Herbarium (http://www.cvh.org. cn) and Global Biodiversity Information Facility (https://www.gbif.org/) in 2017, we found that one distinct specimen from Hainan Island placed under $R$. rubrinervis might represent a new species because it was clearly different from a representative specimen of this species from Guangxi with the characters of shorter fruit and smaller leaf length to width ratio (Figure 1). In order to further test this hypothesis, we re-examined specimens (including type specimens) in herbaria to illustrate the distinct differences of this special Hainan specimen. We also conducted a field survey across the total distribution range of $R$. rubrinervis, including this Hainan population, to collect enough specimens for the examination of their morphological variations at the population level.

\section{Material and methods}

\section{Field surveys}

We examined the specimens of $R$. rubrinervis preserved in the following herbaria: PE, KUN, GXMG, GXMI, GZAC, IBK, IMDY and MNHN (Table 1). In addition, we collected 164 specimens from 18 populations across its total distribution range for morphological comparison and clustering analysis. Voucher specimens were deposited as Zhiqiang Lu 2018XTBG001-Zhiqiang Lu 2018XTBG019 (HITBC), Zhiqiang Lu 2018191001-Zhiqiang Lu 2018191011 (HITBC), Zhiqiang Lu 2018XSBN001Zhiqiang Lu 2018XSBN003 (HITBC), Zhiqiang Lu 2018115001-Zhiqiang Lu 2018115013 (HITBC), Zhiqiang Lu 2018034001-Zhiqiang Lu 2018034007 (HITBC), Zhiqiang Lu 2018027001-Zhiqiang Lu 2018027011 (HITBC), Zhiqiang Lu 2018017001-Zhiqiang Lu 2018017008 (HITBC), Zhiqiang Lu 2018128001-Zhiqiang Lu 2018128012 (HITBC), Zhiqiang Lu 2018041001-Zhiqiang Lu 2018041007 (HITBC), Zhiqiang Lu 2018033001-Zhiqiang Lu 2018033005 (HITBC), Zhiqiang Lu 2018187001-Zhiqiang Lu 2018187003 (HITBC), Zhiqiang Lu 2018141001-Zhiqiang Lu 2018141012 (HITBC), Zhiqiang Lu 2018138001-Zhiqiang Lu 2018138015 (HITBC), Zhiqiang Lu 2018035001-Zhiqiang Lu 2018035006 (HITBC), Zhiqiang Lu 2018106001-Zhiqiang Lu 2018106009 (HITBC), Zhiqiang Lu 2018017001- 

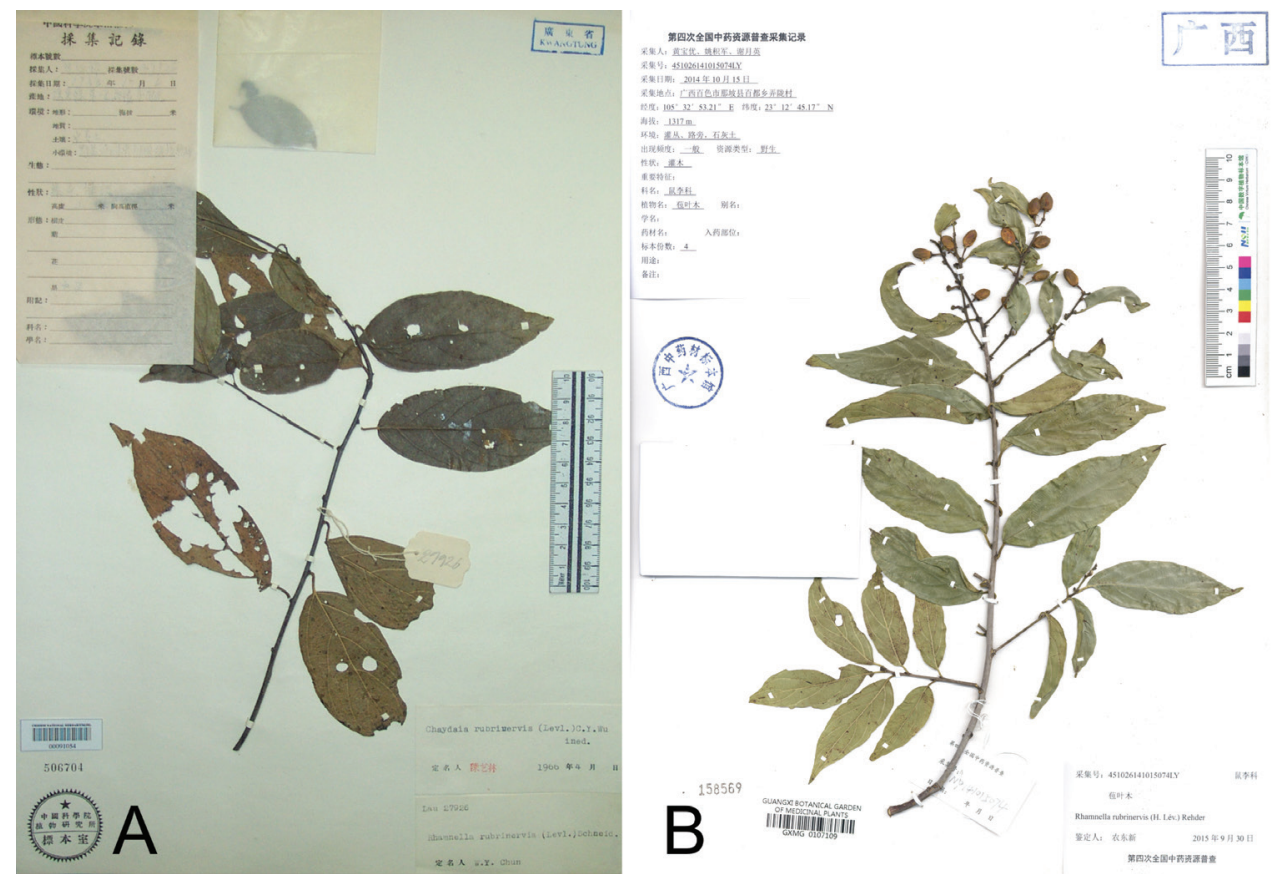

Figure I. The gross morphology of two specimens identified as Rhamnella rubrinervis. A $R$. rubrinervis from Hainan Island (Qionghai, Tayang, 27 Nov 1936, X.Q. Liu 28256, PE) B R. rubrinervis from Guangxi (Baise, Napo, 15 Oct 2014, B.Y. Huang et al. 074LY, GXMG). The leaf length to width ratio and fruit size are totally different between two specimens.

Zhiqiang Lu 2018017008 (HITBC), Zhiqiang Lu 2018HN3001-Zhiqiang Lu $2018 H N 3012$ (HITBC) and Zhiqiang Lu 2018HN3013-Zhiqiang Lu 2018HN3015 (GXMI). In addition, we specifically visited the site of this suspected new species and conducted specific field surveys on its total distribution range and a population census on Hainan Island, from 2018 to 2019.

\section{Morphological analysis}

The newly collected specimens of $R$. rubrinervis were used to conduct morphological comparisons, based on the characters of leaves, flowers, fruit and seeds. We examined their morphological variations within and between populations through the measurement of the typical leaf and fruit for each of 164 newly collected specimens. Seventy five specimens preserved in herbaria were also used to conduct the morphological measurement and comparison (Table 1). However, the measurement of seed characters for these specimens was abandoned, because sizes of seeds could also be reflected by those of fruit (Table 2), in addition that, we could not avoid the damage to them during this process. Finally, a total of 239 specimens and 10 morphological characters were used to carry out the Principal Component Analysis (PCA) (Table 3). 
Table I. Specimens preserved in herbarium used for Principal Component Analysis (PCA) of morphological variations. Those collection sites marked in bold indicate where the additional specimens were collected in this study.

\begin{tabular}{|c|c|c|c|c|c|}
\hline Species name & Collector & Collection number & Collection site & Herbarium & $\begin{array}{c}\text { No. of } \\
\text { specimen }\end{array}$ \\
\hline \multirow[t]{3}{*}{ R. brachycarpa } & Z.Q. $L u$ & 2018HN3001-2018HN3012 & Baoting, Hainan & XTBG & 12 \\
\hline & Z.Q. $L u$ & 2018HN3013-2018HN3015 & Baoting, Hainan & GXMI & 3 \\
\hline & X.Q. Liu & 28256 & Qionghai, Hainan & PE & 1 \\
\hline R. hainanensis & F.A. McClure & 8358 (three copies) & Wuzhishan, Hainan & CAS & 3 (isotypes) \\
\hline \multirow[t]{2}{*}{ R. rubrinervis } & Z. Huang & 34582 & Sanya, Hainan & PE & 1 \\
\hline & Tsang and Fung & 18207 & Danzhou, Hainan & PE & 1 \\
\hline R. tonkinensis & H.F. Bon & 2246 (three copies) & Vietnam & MNHN & 3 (isolectotypes) \\
\hline R. longifolia & G.M. Feng & 11638 & Jinghong, Yunnan & KUN & 1 (isotype) \\
\hline R. crenulata & Handel-Mazzetti & 10758 & Badschai, Guizhou & HT & 1 (isotype) \\
\hline \multirow[t]{31}{*}{ R. rubrinervis } & A. Rehder & 729 & China & $\mathrm{HUH}$ & 1 (holotype) \\
\hline & China-Vietnam team & 1477 (two copies) & N Vietnam & PE, KUN & 2 \\
\hline & Q.W. Wang & $76350,75597,75473,441$ & Jinghong, Yunnan & PE & 4 \\
\hline & G.M. Feng & $11638,14381,159$ & Menghai, Yunnan & PE & 3 \\
\hline & Y.H. Li & $3574,34298,3574,2505$ & Menglun, Yunnan & НITBC & 4 \\
\hline & G.D. Tao & 16289 & Jinuoshan, Yunnan & НITBC & 1 \\
\hline & X.W. Li & 13103,13015 & Yiwu, Yunnan & KUN & 2 \\
\hline & Z.H. Yang & 1424 & Fadou, Yunnan & KUN & 1 \\
\hline & Maguan team & 076,323 & Maguan, Yunnan & IMDY & 2 \\
\hline & Y.Z. Wang et al. & 4388 & Malipo, Yunnan & PE & 1 \\
\hline & Q.W. Wang & 84943,84942 & Yanshan, Yunnan & $\mathrm{PE}$ & 2 \\
\hline & S.W. Yu & 86011,860117 & Yanshan, Yunnan & KUN & 2 \\
\hline & Beijing team & 893045,896924 & Tian'e, Guangxi & PE & 2 \\
\hline & S.X. Yu & 337 & Napo, Guangxi & GXMG & 1 \\
\hline & Anonymous & 63,402 & Location unknown & KUN & 2 \\
\hline & China-Japan team & 100828 & Xingyi, Guizhou & KUN & 1 \\
\hline & Guizhou team & 8180,8427 & Xingren, Guizhou & KUN & 2 \\
\hline & J.C. Yang & LHOO72 & Longtan, Guangxi & IBK & 1 \\
\hline & Anonymous & 683 & Liuzhou, Guangxi & IBK & 1 \\
\hline & Lingyun team & $\begin{array}{l}19 L Y, 08 L Y, 48 L Y, 49 L Y, \\
58 L Y, 74 L Y, 51 L Y, 04 L Y, 05\end{array}$ & Lingyun, Guangxi & GXMG & 9 \\
\hline & Tianlin team & 031 (two copies), 005 & Tianlin, Guangxi & GXMG & 3 \\
\hline & Yongfu team & $03 L Y$ & Yongfu, Guangxi & GXMG & 1 \\
\hline & Anonymous & $00747,99 L Y$ & Tian'e, Guangxi & $\begin{array}{l}\text { IBK, } \\
\text { GXMG }\end{array}$ & 2 \\
\hline & B.Y. Huang & 23672 & Shangsi, Guangxi & GXMG & 1 \\
\hline & C.C. Huang & 16994, 00938 & Luocheng, Guangxi & GXMI & 2 \\
\hline & $X . X$. Chen & $02793,02323,2967$ & Chongzuo, Guangxi & GXMI & 3 \\
\hline & Y.S. Huang et al. & LYJX0657, LYJX0458 & Jingxi, Guangxi & IBK & 2 \\
\hline & K.M. Lan & 870007,870060 & Daozhen, Guizhou & GZAC & 2 \\
\hline & R.C. Peng & ML0367 & Huanjiang, Guangxi & IBK & 1 \\
\hline & Z.Y. Cao & 1135,597 & Ceheng, Guizhou & $\mathrm{PE}$ & 2 \\
\hline & Y. Jiang & 7045 & Dushan, Guizhou & PE & 1 \\
\hline
\end{tabular}


Table 2. Morphological characters of Rhamnella rubrinervis and R. brachycarpa at the population level. Traits that differ between species are marked in bold.

\begin{tabular}{|c|c|c|}
\hline Characters & Rhamnella rubrinervis & Rhamnella brachycarpa \\
\hline \multicolumn{3}{|l|}{ LEAF } \\
\hline Shape and size & $\begin{array}{l}\text { Leaf blade oblong or ovate-oblong, } 5.4-14.4 \\
\times 1.7-5.1 \mathrm{~cm} \text {, length to width ratio } \\
\text { (2.5) 2.8-3.9; base commonly rounded, rarely } \\
\text { cuneate, margin inconspicuously remotely } \\
\text { serrate or subentire; apex acuminate to long } \\
\text { acuminate; bracteole leaf similar to leaves in } \\
\text { vegetative branches, but smaller }\end{array}$ & $\begin{array}{l}\text { Leaf blade elliptic-ovate, } 5.8-10.3 \times \\
3.1-4.8 \mathrm{~cm} \text {, length to width ratio } \mathbf{1 . 9 - 2 . 4} \text {; } \\
\text { base cuneate or nearly rounded, margin } \\
\text { inconspicuously remotely serrate or subentire; } \\
\text { apex short acuminate or acute; bracteole } \\
\text { leaf similar to leaves in vegetative branches, } \\
\text { but smaller }\end{array}$ \\
\hline Length of petiole & $3-9 \mathrm{~mm}$ & $7-12 \mathrm{~mm}$ \\
\hline $\begin{array}{l}\text { Number of lateral veins on } \\
\text { each side of midvein }\end{array}$ & $5-8$ & $5-7$ \\
\hline $\begin{array}{l}\text { Average distance between } \\
\text { lateral veins located in the } \\
\text { middle of leaf }\end{array}$ & $3-8 \mathrm{~mm}$ & $3-6 \mathrm{~mm}$ \\
\hline FLOWER & & \\
\hline $\begin{array}{l}\text { Number of flowers for each } \\
\text { axillary cyme }\end{array}$ & $2-10$ & $2-9$ \\
\hline Length of pedicel & $2-5$ & $3-5$ \\
\hline Shape and size & $\begin{array}{l}\text { Flower diameter ca. } 4 \mathrm{~mm} \text {; sepals triangular, } \\
\text { ca. } 2 \mathrm{~mm} \text {; stamens involute by petals, ca. } 2 \\
\mathrm{~mm} \text { in length }\end{array}$ & $\begin{array}{l}\text { Flower diameter ca. } 4 \mathrm{~mm} \text {; sepals triangular, } \\
\text { ca. } 2 \mathrm{~mm} \text {; stamens involute by petals, ca. } 2 \\
\mathrm{~mm} \text { in length }\end{array}$ \\
\hline \multicolumn{3}{|l|}{ FRUIT } \\
\hline Size of fleshy fruit & $10.2-12.1 \times 10.1-12.5 \mathrm{~mm}$ & $8.7-10.9 \times 7.5-10.6 \mathrm{~mm}$ \\
\hline Size of dried fruit & $8.2-11.1 \times 4.2-5.8 \mathrm{~mm}$ & $6.5-7.5 \times 4.7-6.0 \mathrm{~mm}$ \\
\hline $\begin{array}{l}\text { Length to width ratio of } \\
\text { dried fruit }\end{array}$ & $1.6-2.2$ & $1.3-1.5$ \\
\hline $\begin{array}{l}\text { Length of fruiting pedicel } \\
\text { SEED }\end{array}$ & $3-6 \mathrm{~mm}$ & $4-6 \mathrm{~mm}$ \\
\hline Size of seed & $7.1-9.9 \times 4.0-5.5 \mathrm{~mm}$ & $5.0-7.0 \times 4.5-5.5 \mathrm{~mm}$ \\
\hline $\begin{array}{l}\text { Length to width ratio of } \\
\text { seed }\end{array}$ & $1.6-2.1$ & $0.9-1.5$ \\
\hline Seed apex & Rarely mucronate & Mucronate \\
\hline
\end{tabular}

Table 3. Morphological characters measured for Principal Component Analysis (PCA) based on 239 specimens.

\begin{tabular}{lccc}
\hline Character number & State & Unit & Coding (if qualitative) \\
\hline LEAF & Length & $\mathrm{cm}$ & \\
1 & Width & $\mathrm{cm}$ & \\
2 & Length to width ratio & Ratio & \\
3 & Length of petiole & $\mathrm{cm}$ & \\
4 & Apex & Qualitative & 2 = Short acuminate or acute \\
5 & Base rounded or cuneate & $1=$ Long acuminate or acuminate \\
& & Qualitative & $2=$ Cuneate \\
6 & Count & 1 = Rounded \\
7 & Number of lateral veins on each side of midvein & Count & \\
DRIED FRUIT & Length & mm & \\
8 & Width & mm & \\
9 & Length to width ratio & Ratio & \\
10 & & & \\
\hline
\end{tabular}




\section{Results}

Our specific field survey on the special record on Hainan Island showed that no extant tree similar to $R$. rubrinervis existed in Tayang Township, Qionghai City (Figure 1A) and that the habitat was badly destroyed by human activity. However, we finally explored two new $R$. rubrinervis populations with smaller leaf length to width ratio and shorter fruit in Baoting County during our field surveys in 2018 (Table 1; Figures 2-4). Morphological comparison at the population level was conducted, showing three Hainan populations distinctly differed from those of $R$. rubrinervis from other regions with the smaller leaf length to width ratio (1.9-2.4 vs. (2.5) 2.8$3.9)$, shorter fruit $(6.5-7.5 \mathrm{~mm}$ vs. $8.2-11.1 \mathrm{~mm})$, smaller fruit length to width ratio (1.3-1.5 vs. 1.6-2.2), dumpier seeds $(5.0-7.0 \times 4.5-5.5 \mathrm{~mm}$ vs. $7.1-9.9 \times 4.0-5.5$ $\mathrm{mm})$, smaller seed length to width ratio (0.9-1.5 vs. 1.6-2.1) and mucronate seed apices (Figures 3-4; Table 2). Differences were also found in leaf base shape, petiole length $(3-9 \mathrm{~mm}$ vs. $7-12 \mathrm{~mm})$ and fleshy fruit size $(8.7-10.9 \times 7.5-10.6 \mathrm{~mm}$ vs. $10.2-12.1 \times 10.1-12.5 \mathrm{~mm})$. No significant difference in flowers was found between the distinct Hainan populations and those of $R$. rubrinervis from other regions. A further PCA of all closely related specimens (including historical type specimens of four published synonyms), based on 10 morphological characters, was carried out (Table 3), distinguishing these three Hainan populations (in Baoting and Qionghai) and those of $R$. tonkinensis and $R$. rubrinervis from other regions into two major groups (Figure 5). One of the two groups merely represented these distinct Hainan populations; the remaining populations of $R$. tonkinensis and $R$. rubrinervis formed the other group. The first principal component axis (PC1; accounting for 38.99\% of the variation) significantly separated these distinct Hainan populations from the other two species, while the second principal component axis (PC2; accounting for $20.87 \%$ of the variation) failed in separating both groups (Figure 5).

\section{Discussion}

In this study, we demonstrated that three distinct Hainan populations previously placed under $R$. rubrinervis should be described as a new species, based on the distinct morphology and clustering analysis at the population level. Morphological comparison showed that they differ from those of $R$. rubrinervis from other regions in mucronate seed apices, shorter fruit, dumpier seeds and smaller length to width ratios of leaves, fruit and seeds. PCA analysis further clustered these special Hainan populations into a separated group distinctly different from those of $R$. rubrinervis and $R$. tonkinensis from other regions (including historical type specimens of those published synonyms). Our results also showed that $R$. rubrinervis and $R$. tonkinensis had a similar morphology, indicating the obscure species boundary between them. This finding is consistent with a previous study (Fan and Yang 1997). Obviously, these special Hainan populations are distinctly different from all extant relatives from other regions (Chen and Carsten 2007). Given this, we describe them in the following as a new species. 


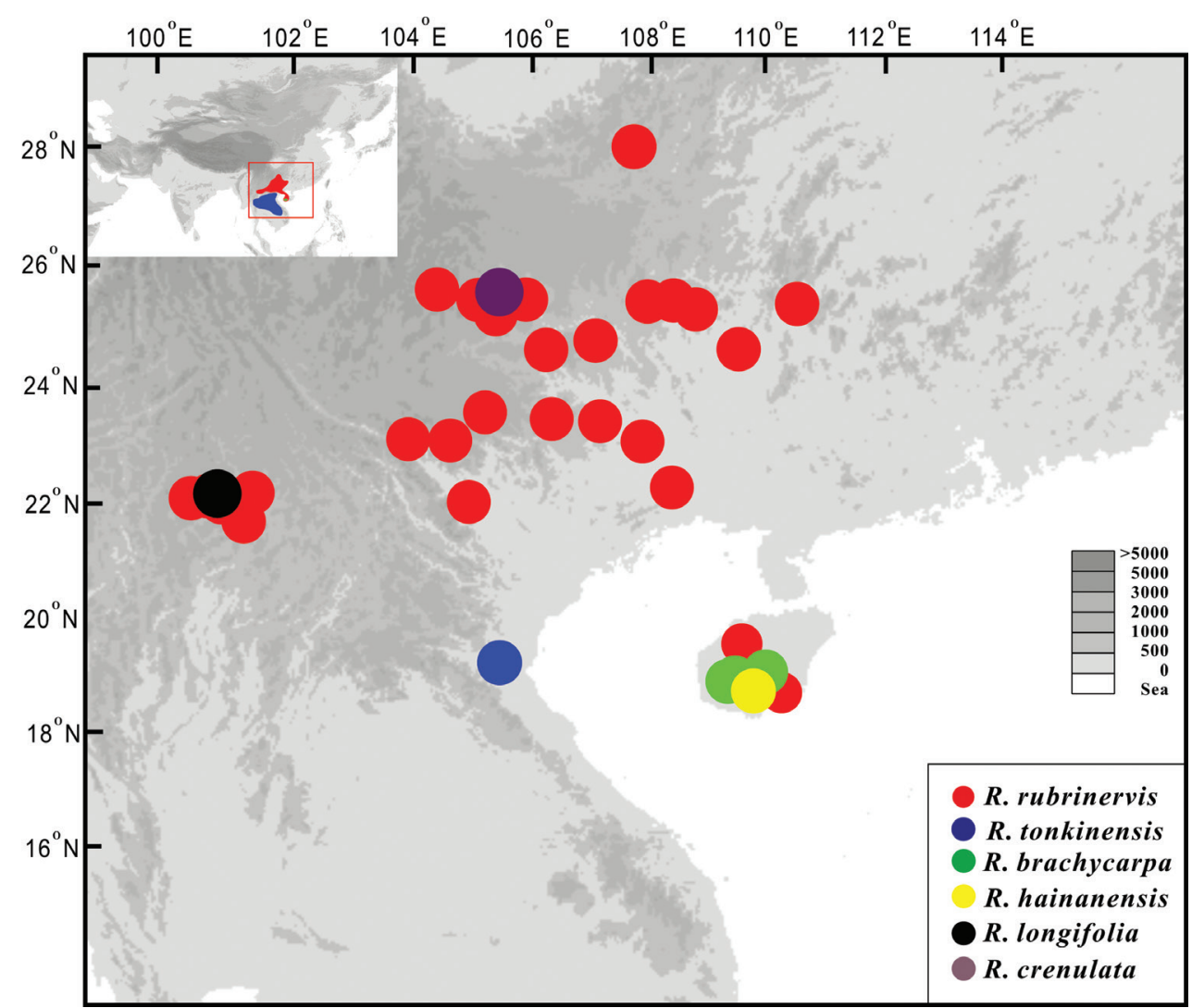

Figure 2. Distribution and locations of R. brachycarpa, R. rubrinervis and R. tonkinensis, based on field surveys, Chinese Virtual Herbarium (http://www.cvh.org.cn/) and Global Biodiversity Information Facility (https://www.gbif.org/).

\section{Taxonomic treatment}

\section{Rhamnella brachycarpa Z. Qiang Lu \& Y. Shuai Sun, sp. nov.} urn:lsid:ipni.org:names:60479375-2

Figures 3, 4

Diagnosis. Rhamnella brachycarpa differs from $R$. rubrinervis and $R$. tonkinensis by leaf length to width ratio of 1.9-2.4 (compared to 2.5-3.9 in the related species) and dried fruit 6.5-7.5 × 4.7-6.0 $\mathrm{mm}$ in size (compared to $8.2-11.1 \times 4.2-5.8 \mathrm{~mm}$ in $R$. rubrinervis and $R$. tonkinensis) with length to width ratio of 1.3-1.5 (compared to 1.6-2.2).

Type. CHINA. Hainan: Baoting County, Xian'an, 109 25'34"E, 18 $35^{\circ} 37^{\prime \prime} \mathrm{N}$, 650 m alt., forest edge, 16 Oct 2018, Z.Q. Lu 2018HN3001 (holotype, HITBC; isotypes, HITBC and GXMG).

Description. Small trees or climbing vines, evergreen. Young branches sparsely pilose or glabrous; older branches reddish-brown, grey-brown or grey, glabrous. Leaves alternate; stipules lanceolate, persistent; petiole $0.7-1.2 \mathrm{~cm}$ long, glabrous, narrowly 


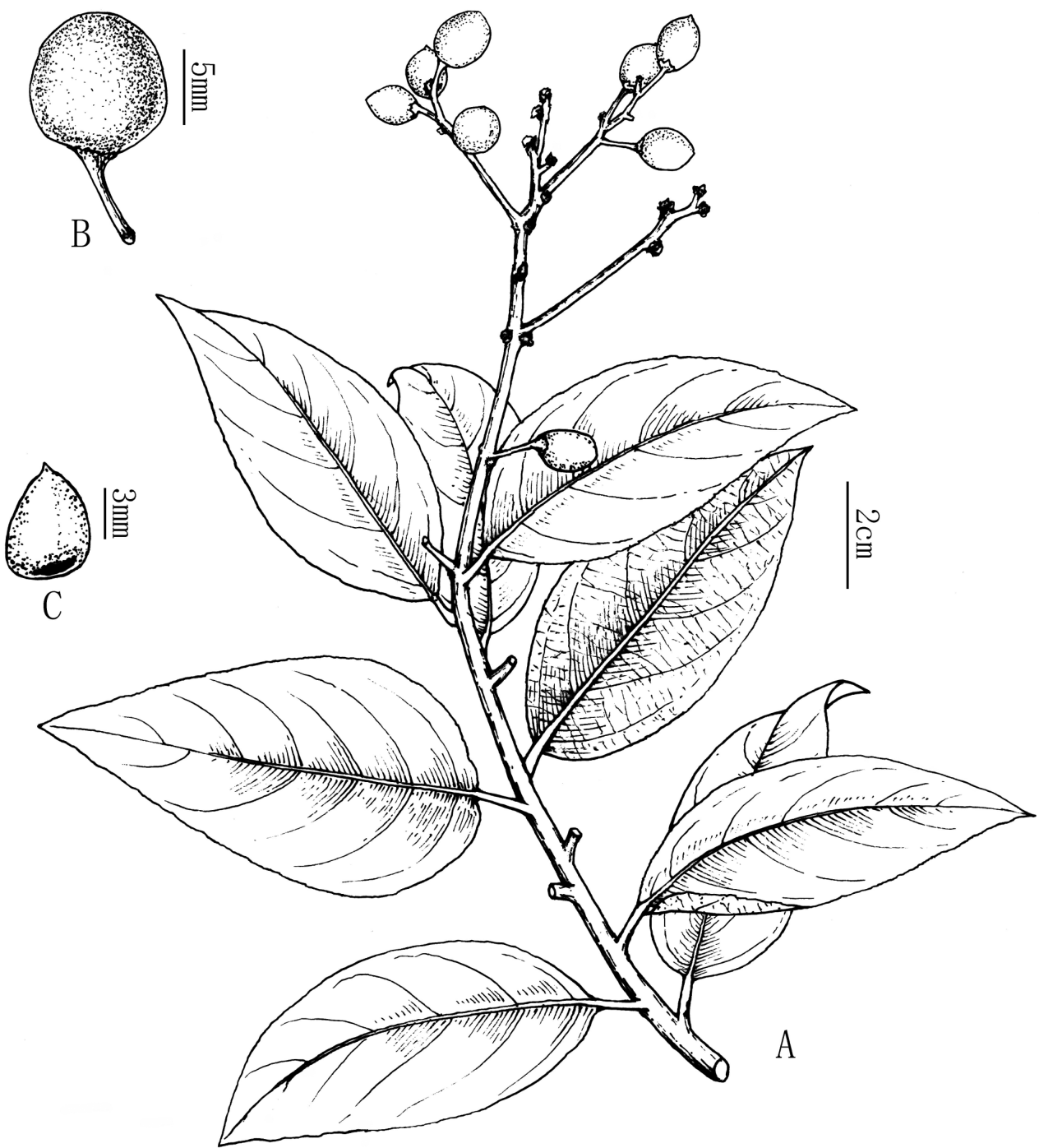

Figure 3. Rhamnella brachycarpa Z. Qiang Lu \& Y. Shuai Sun, sp. nov., drawn from the tree of Z.Q. Lu $2018 H N 3001$.

grooved on the upper surface; leaf blade abaxially dark green, shiny, adaxially pale green, elliptic-ovate, $5.8-10.3 \times 3.1-4.8 \mathrm{~cm}$, leathery, abaxially glabrous, adaxially glabrous, lateral veins 5-7 pairs, slightly impressed abaxially, prominent adaxially, base cuneate or nearly rounded, margin subentire, conspicuously serrate when seedlings, apex shortly acuminate or acute. Flowering branches axillary, rarely not, $7-18 \mathrm{~cm}$ long, glabrous. Flowers bisexual, ca. $4 \mathrm{~mm}$ diam., $4-$ or 6 -merous, few to 2 or 9 in axillary cymes, subsessile or shortly pedunculate at bracteole leaf of flowering branches; bracteole leaf similar to leaves in vegetative branches, but smaller, 1.5-5.0 $\times 0.9-2.3$ $\mathrm{cm}$. Pedicel 3.3-5.2 mm long, glabrous. Sepals triangular, ca. $2 \mathrm{~mm}$, adaxially mid- 

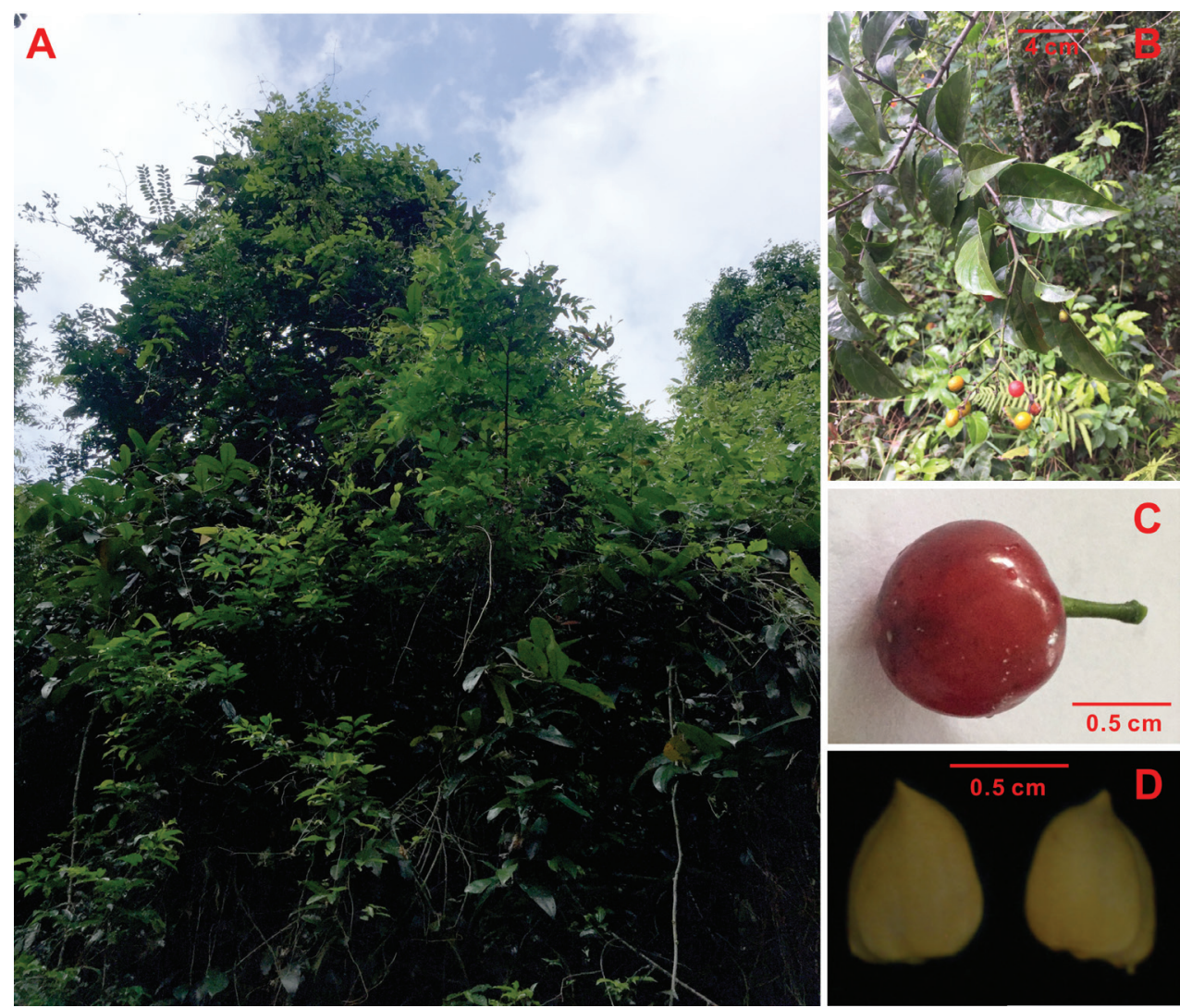

Figure 4. Rhamnella brachycarpa Z. Qiang Lu \& Y. Shuai Sun. A The habitat B Branches with leaves and fruit $\mathbf{C}$ Fruit $\mathbf{D}$ Seeds.

vein raised, rostellate at lower middle. Petals obovate, shortly clawed. Stamens involute by petals, ca. $2 \mathrm{~mm}$ long. Disc rounded, thick. Ovary globose, not immersed in disc. Drupe purple-red or orange at maturity, ovoid-cylindrical or globose, 8.7-10.9 $\times 7.5-10.6 \mathrm{~mm}, 6.5-7.5 \times 4.7-6.0 \mathrm{~mm}$ when dried, base with persistent calyx tube; fruiting pedicel 4.3-6.2 mm, glabrous, 1-loculed, 1-seeded; seed dumpy, apex mucronate, smooth on the surface, $5.0-7.0 \times 4.5-5.5 \mathrm{~mm}$.

Etymology. In contrast with relatives, all individuals from these distinct Hainan populations have shorter fruit; we therefore give the epithet Rhamnella brachycarpa.

Phenology. Flowering from May to September and fruiting from July to October.

Habitat, distribution and conservation. According to our field surveys and records in Chinese Virtual Herbarium (CVH), R. brachycarpa has been found at three sites on Hainan Island (Baoting County: Xian'an and Shijia; Qionghai City: Tayang). Only two small populations with 45 individuals (including only 22 mature trees) have been found in Baoting, while no extant tree has been found in the Qionghai population due to the destruction of the habitat. Of the two small populations in Baoting, with a separation distance of about $900 \mathrm{~m}$, one consists of only three 


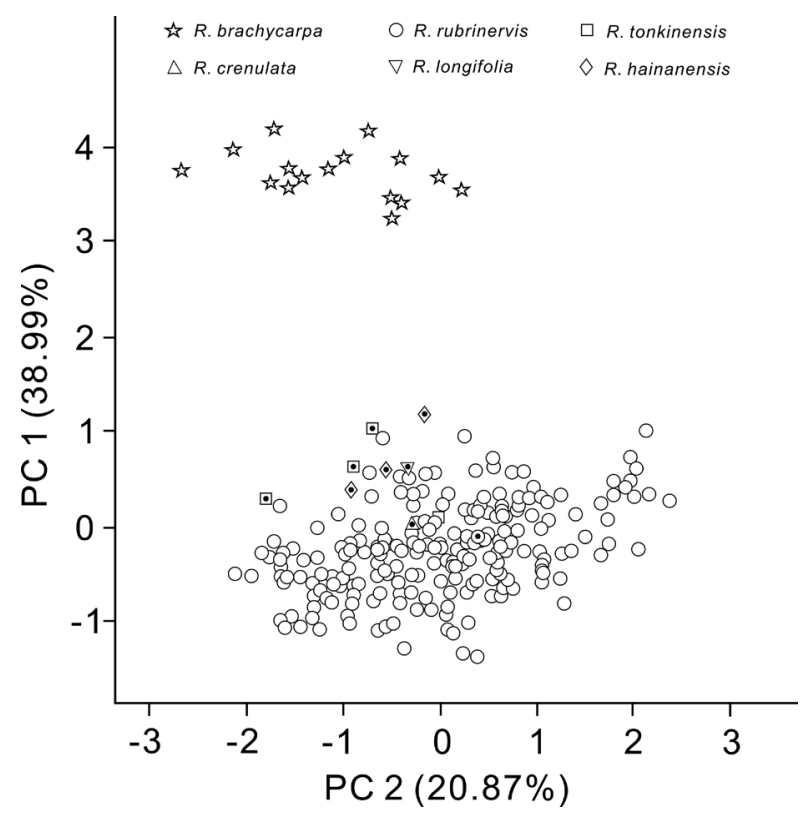

Figure 5. Morphological clustering based on Principal Component Analysis. R. crenulata, R. longifolia and $R$. hainanensis are synonyms of $R$. rubrinervis. The black dots indicate the designated type specimens.

mature trees without seedlings; the second population has 19 mature trees and 23 immature trees. All mature trees are more than $3.1 \mathrm{~m}$ in height and less than $1.8 \mathrm{~m}$ is observed for all immature trees. Forty five individuals of this new species sparsely grow along the roadsides and in forest edges or thick forest. Mature trees with climbing habit only grow in thick forest or forest edges with high canopies, but those with erect habit prefer to grow along roadsides or in forest edges without high canopies. Nevertheless, all these immature trees, sparsely growing along the roadsides and in forest edges or thick forest, present the erect habit. The rarity of this new species may be partially due to human activity because the habitat is also suitable for cultivating rubber trees and other economic plants. Comparing to the number of mature trees, the number of immature trees further indicates a decreasing population trend. In addition, all these trees are distributed in a total area of approximately $0.7 \mathrm{~km}^{2}$. No population was found during repeated field surveys of the surrounding areas. According to the IUCN Categories and Criteria (IUCN 2016), the species is classified as "Critically Endangered" (CR). Therefore, it will be necessary to pay close attention to the conservation of this new species.

Additional specimens examined. CHINA. Hainan: Qionghai City, Tayang, open forest, 27 Nov 1936, X.Q. Liu 28256 (PE); Baoting County, Xian'an, $109^{\circ} 25^{\prime} 34^{\prime \prime E}, 18^{\circ} 35^{\prime} 37^{\prime \prime} \mathrm{N}, 650 \mathrm{~m}$ alt., forest edge, roadside and thick forest, 16 Oct 2018, Z.Q. Lu 2018HN3002-Z.Q. Lu $2018 H N 3012$ (HITBC); Baoting County, Shijia, $109^{\circ} 25^{\prime} 42^{\prime \prime E}, 18^{\circ} 36^{\prime} 02^{\prime \prime N}, 680 \mathrm{~m}$ alt., forest edge, 17 Oct 2018, Z.Q. Lu 2018HN3013-Z.Q. Lu 2018HN3015 (GXMI). 


\section{Acknowledgements}

We thank Dr. Huizhe Feng for the help in collecting samples and Mr. Xincheng Qu for drawing the picture. This work is supported by grants from "1000 Youth Talents Plan" of Yunnan Province, CAS "Light of West China" Program and start-up research fund of XTBG (No. B18114BN).

\section{References}

Chen YL, Carsten S (2007) Rhamnaceae. Flora of China, vol 12. Science Press, Beijing. Fan GS, Yang CB (1997) A study on classification and distribution of genus Chaydaia. Journal of Southwest Forestry College 17(3): 1-4.

Hauenschild F, Matuszak S, Muellner-Riehl AN, Favre A (2016) Phylogenetic relationships within the cosmopolitan buckthorn family (Rhamnaceae) support the resurrection of Sarcomphalus and the description of Pseudoziziphus gen. nov. Taxon 65(1): 47-64. https://doi. org/10.12705/651.4

IUCN (2016) Guidelines for Using the IUCN Red List Categories and Criteria. Version 12. Prepared by the Standards and Petitions Subcommittee. http://www.iucnredlist.org/documents/RedListGuidelines.pdf 